\title{
Origin of Endotoxemia Influences the Metabolic Response to Endotoxin in Dogs
}

\author{
Hazra S. Moeniralam, M.D.,* Willem A. Bemelman, M.D.,† J ohannes A. Romijn, M.D.,* Erik Endert,* \\ Mariette T. Ackermans, Ph.D.,* J . J an B. van Lanschot, M.D.,† \\ Rob C. Hermsen, $\ddagger$ and Hans P. Sauerwein, M.D.*

\begin{abstract}
*Department of Endocrinology and Metabolism and †Department of Surgery, Academic Medical Center, University of Amsterdam, Meibergdreef 9, 1105 AZ Amsterdam, The Netherlands; Department of Microbiology,
\end{abstract} \\ University Hospital, Nijmegen, The Netherlands
}

Submitted for publication April 9, 1997

Different routes of endotoxin administration have been used to mimic inflammatory and metabolic responses observed during sepsis. Because the origin of endotoxemia may affect the reactions to endotoxin, we compared the induction of tumor necrosis factor (TNF), interleukin-6 (I L-6), hormones, and glucose production after endotoxin $(1.0 \mu \mathrm{g} / \mathrm{kg}$ Escherichia coli 0111:B4) administration into a peripheral $(n=8)$ versus the portal $(n=8)$ vein in anesthetized dogs. Prior to endotoxin, a laparotomy was performed for cannulation of hepatic vessels. To evaluate the effects of surgery and anesthesia, we also studied the effects of peripheral endotoxin administration in six awake dogs. The rate of appearance of glucose was measured by primed continuous infusion of $\left[6,6-{ }^{2} \mathrm{H}_{2}\right]$ glucose. In anesthetized dogs, arterial concentrations of TNF and I L6 increased after endotoxin administration $(P<0.01$ vs basal; NS between groups). Net hepatic TNF production was increased after endotoxin administration (peripheral vs portal endotoxin administration: $533 \pm 177$ vs $2135 \pm 1127 \mathrm{ng} / \mathrm{min}$, both $P<0.05$ vs basal; NS between groups). Net hepatic IL-6 production was stimulated only after portal endotoxin delivery (from $86 \pm$ 129 to $4740 \pm 1899 \mathrm{ng} / \mathrm{min}, \mathrm{P}<0.05 ; \mathrm{NS}$ between groups). Although there were no differences in neuroendocrine activation, portal endotoxin administration resulted in decreased glucose production compared with peripheral administration (13.6 \pm 0.9 vs $16.8 \pm 1.2$ $\mu \mathrm{mol} / \mathrm{kg} \cdot \mathrm{min}, \mathrm{P}<0.05)$. In contrast to anesthetized dogs, endotoxin increased glucose production considerably in awake dogs from $13.8 \pm 1.2$ to $24.2 \pm 3.2 \mu \mathrm{mol} /$ $\mathbf{k g} \cdot \min (\mathbf{P}<0.05 ; \mathbf{P}<0.05$ vs anesthetized dogs). The contribution of anesthesia and surgery increased the endotoxin-induced IL-6 response by $\sim 350 \%$ compared with the effect of endotoxin in awake dogs $(P<0.01)$. In conclusion, there are no major differences in the responses to endotoxin between peripherally treated and portally treated dogs, except for differences in glucose production. Portal delivery compared with systemic delivery of endotoxin alters hepatic metabolism through nonendocrine mechanisms, reflected in decreased glucose production. The inflammatory, endo- crine, and metabolic effects of endotoxin are altered by the combination of surgery and anesthesia. $\odot 1997$ Academic Press

Key Words: cytokines; hormones; liver; glucose production; stable isotopes; portal vein.

\section{INTRODUCTION}

Endotoxin is often used to mimic the inflammatory and metabolic responses during sepsis. In the literature various routes of administration have been used. In these experiments endotoxin was given intraperitoneally (rats), intravenously (dogs, rats, humans), or into the portal vein (dogs, swine) [1-10]. Endotoxin is readily cleared from the circulation by macrophages with concomitant macrophage activation, resulting in the release of inflammatory mediators, including tumor necrosis factor (TNF) and interleukin-6 (IL-6) [11]. As the liver contains a major proportion of the total body macrophage content, it is possible that endotoxin delivery by portal and systemic routes result in different cytokine responses. Concomitantly, this difference in cytokine response may lead to a difference in hepatic glucose metabolism.

The objective of this study was to compare the inflammatory, endocrine, and metabolic responses to administration of a bolus of endotoxin into a peripheral versus the portal vein in anesthetized dogs. High-dose endotoxin causes hemodynamic instability and decreased organ perfusion $[1,6,8,10,12]$. Because circulatory shock itself may induce metabolic changes, we injected that dose of endotoxin $(1.0 \mu \mathrm{g} / \mathrm{kg})$ that induces significant secretion of TNF and IL-6 in anesthetized dogs without the induction of circulatory shock [13]. To control for the effects of surgery and anesthesia, we also studied the effects of peripheral endotoxin administration in awake dogs.

\section{MATERIALS AND METHODS}

\section{Animals}

Twenty-two male mongrel dogs (weight: $28 \pm 2 \mathrm{~kg}$, mean \pm SEM) were studied. Sixteen were studied under general anesthesia (portal 
endotoxin administration $n=8$; peripheral administration, $n=8$ ). Six awake dogs served as the control group. Prior to the study all dogs were observed for 2 weeks. Only dogs with normal stools, no febrile disease, and normal physical examination and laboratory results were included. The dogs were fed a standard diet once a day consisting of $64 \%$ carbohydrate, $7 \%$ fat, $26 \%$ protein, $3 \%$ fiber, based on dry weight (D. B. Brok, Hope Farms, Woerden, The N etherlands). The study was approved by the Ethical Committee for Animal Experiments and performed according to the guidelines of the Dutch Law for Animal Experiments.

\section{Operative Procedure}

Awake dogs. To get used to the experimental procedure, these dogs were trained daily in the experiment room to lie quiet for a few hours. Four days before each experiment a femoral artery catheter was inserted during general anesthesia [1\% isoflurane (Forene, Abbott Laboratories, Queensbourough, Kent, United Kingdom) and $\mathrm{N}_{2} \mathrm{O} / \mathrm{O}_{2}$ (1:1) ventilation]. After insertion, the catheter was filled with heparin $(200 \mathrm{U} / \mathrm{ml})$, closed, and placed in a subcutaneous pocket.

Anesthetized dogs. After an overnight fast (18 h) the dogs were anesthetized, intubated, and ventilated artificially. General anesthesia was induced by intramuscular injection of xylazine $(0.15 \mathrm{ml} / \mathrm{kg}$; Rompun, Bayer, Germany), ketamine hydrochloride $(20 \mathrm{mg} / \mathrm{kg}$; Ae scoket, Aesculaap BV, The Netherlands), and atropine $(0.05 \mathrm{mg} / \mathrm{kg}$; Centrafarm Services BV, Etten-Leur, The Netherlands) and maintained by intravenous sufentanil $(1.5 \mu \mathrm{g} / \mathrm{kg} \cdot \mathrm{h}$; J anssen-Cilag BV, Tilburg, The Netherlands), $1 \%$ isoflurane, and $\mathrm{N}_{2} \mathrm{O} / \mathrm{O}_{2}(1: 1)$ ventilation. A urine catheter and a rectal temperature probe were inserted. A Swan Ganz thermal dilution catheter was positioned in the pulmonary artery through the external jugular vein. A femoral artery catheter was inserted for blood sampling and continuous intraarterial blood pressure monitoring.

Subsequently, the abdominal cavity was opened through a midline incision. The gastroduodenal vein was ligated at its junction with the portal vein. Doppler flow probes (20-MHz pulsed Doppler modules, epoxy probe, obtained from G.J. Hartley, Baylor College of Medicine, Houston, TX) were positioned around the hepatic artery and the portal vein. Flexible Tygon catheters (S54-HL, Norton Company, Rubber BV, Hilversum, The Netherlands, ID 0.040-in. i.d., 0.070-in. o.d., 15-in. length) were inserted into the portal and hepatic veins, located between the left medial and left lateral lobes of the liver. One catheter was advanced over $5 \mathrm{~cm}$ into the portal vein, with thetip distal to the portal vein Doppler flow probe. The other catheter was advanced anterogradely, over $2 \mathrm{~cm}$, into the hepatic vein. The surgical preparation of the animal model lasted $\sim 120$ min. After surgery the catheters were flushed with saline and kept patent by a slow infusion of saline.

\section{Experimental Design}

Awake dogs. On the morning of the experiment, the skin around the pocket was anesthetized with lidocaine and opened. Subsequently, the femoral artery catheter was obtained from the pocket and attached to a monitor for continuous intraarterial blood pressure monitoring and blood sampling.

Anesthetized and awake dogs. Each study period started at 8.00 AM after an overnight fast of $18 \mathrm{~h}$. A catheter was inserted into the right cephalic vein for infusion of saline and administration of endotoxin. Another catheter was inserted into the left cephalic vein for $\left[6,6-{ }^{2} \mathrm{H}_{2}\right]$ glucose infusion. After obtaining blood samples for determination of basal enrichment, a primed $(17.6 \mu \mathrm{mole} / \mathrm{kg})$, continuous $(0.22 \mu \mathrm{mole} / \mathrm{kg} \cdot \mathrm{min})$ infusion of filter-sterilized $\left[6,6-{ }^{2} \mathrm{H}_{2}\right]$ glucose (99\%; Isotec Inc., Miamisburg, OH) was started at $\mathrm{t}=-120 \mathrm{~min}$, using a calibrated syringe infusion pump. After 120 min of infusion of $\left[6,6-{ }^{2} \mathrm{H}_{2}\right]$ glucose, four blood samples were taken at intervals of 5 min for measurement of glucose enrichments. In addition blood was sampled for analysis of concentrations of hormones and cytokines. Subsequently, a bolus dose of $1.0 \mu \mathrm{g} / \mathrm{kg}$ Escherichia coli endotoxin was injected into either the right cephalic vein in awake $(n=6)$ and anesthetized $(n=8)$ dogs or into the portal vein in anesthetized dogs $(n=8)$.
Endotoxin derived from E. coli (0111:B4, Lot 31H4000, phenol extracted; Sigma Chemical Co., St. Louis, MO) was suspended in sterile pyrogen-free saline. A stock solution of $100 \mu \mathrm{g} / \mathrm{ml}$ was made, divided into several plastic tubes (Costar, Cambridge, MA), and kept frozen at $-20^{\circ} \mathrm{C}$. Before use the endotoxin solution was thawed at $37^{\circ} \mathrm{C}$, vortexed for $3 \mathrm{~min}$, diluted, and vortexed again for $10 \mathrm{~min}$.

In the awake dogs, mean arterial blood pressure and heart rate were monitored continuously and recorded every $15 \mathrm{~min}$. I n the anesthetized dogs, mean arterial blood pressure, heart rate, el ectrocardiogram, central venous pressure, pulmonary artery pressure, and pulmonary artery wedge pressure were monitored continuously and recorded at intervals of $15 \mathrm{~min}$. Cardiac output was determined by thermal dilution technique using a cardiac output computer ( $E$ dwards Labs, Santa Ana, CA). Blood flow in the hepatic artery and portal vein was monitored continuously with Doppler flow probes, connected to a flowmeter (three-channel ultrasonic flow-dimension system; G. J . Hartley, Baylor College of Medicine) [14] and recorded every $10 \mathrm{~min}$. Total hepatic blood flow was the sum of the blood flow through the hepatic artery and portal vein.

Blood samples for the determination of glucose enrichment and plasma concentrations of glucose, insulin, epinephrine, norepinephrine, glucagon, and cortisol were collected hourly from the femoral artery. Blood samples for the determination of plasma concentration of TNF and IL-6 were collected hourly and also 30 and 90 min after endotoxin administration from the femoral artery and (in anesthetized dogs) from the portal vein and a hepatic vein.

The observation period after endotoxin administration lasted 240 $\mathrm{min}$. At the end of each experiment the correct position of the catheters was confirmed radiographically. Subsequently, the dogs were sacrificed by intravenous injection of sodium pentobarbital.

\section{Sample Processing}

Blood was collected in prechilled tubes and stored on ice. Immediately after sampling the blood samples were centrifuged $\left(3000 \mathrm{~g}, 4^{\circ} \mathrm{C}\right.$, $10 \mathrm{~min}$ ) and plasma was stored at $-20^{\circ} \mathrm{C}$ until determination. Blood for analysis of insulin, cortisol, TNF , IL-6, and $\left[6,6-{ }^{2} \mathrm{H}_{2}\right]$ glucose was collected in heparinized tubes. Whole blood was added to reduced glutathione-EGTA buffer and trasylol for the determination of catecholamines and glucagon, respectively.

\section{Biochemical Analysis}

All measurements were performed in duplicate. All samples of each animal were analyzed in the same run. Plasma insulin concentration was measured by radioimmunoassay (RIA) (Insulin RIA 100, Pharmacia Diagnostics AB, U ppsala, Sweden; detection limit, $2 \mathrm{mU}$ / liter), as was plasma glucagon (Daiichi Radioisotope Laboratories, Tokyo, J apan; detection limit, 15 ng/liter; glucagon antiserum elicited in guinea pigs against pancreatic specific glucagon; cross-reactivity with glucagon-like substances of intestinal origin less than $1 \%$ ). Plasma catecholamine concentrations were measured by HPLC and electrochemical detection, after purification on Biorex 70 and concentration by solvent extraction [15], and cortisol by fluorescence polarization immunoassay on Technical Device X (Abbott Laboratories, Chicago, IL; detection limit, was 50 nmol/liter).

TNF bioactivity in plasma was measured with a WEHI 164 subclone 13 line (kindly provided by W.A. Buurman, Academic Hospital, Maastricht, The Netherlands). The WEHI assay is based on the cytotoxic action of TNF on this fibroblast cell line [16]. TNF standard contained recombinant human TNF (Ernst-Boehringer, Vienna, Austria), which was serially diluted [16]. The detection limit was 10 $\mathrm{pg} / \mathrm{ml}$. IL-6 bioactivity was measured with an IL-6-dependent B-9 hybridoma cell line (kindly provided by L.A. Aarden, Central Laboratory of the Netherlands Red Cross Blood Transfusion Service, Amsterdam, The Netherlands) [17]. The detection limit of the I L- 6 assay was $1 \mathrm{pg} / \mathrm{ml}$. IL-6 standard contained human recombinant IL-6 (HECS; Costar, Badhoevedorp, The Netherlands), which was serially diluted.

Glucose concentrations and enrichments were determined by gas chromatography-mass spectrometry (Gas Chromatograph Model 5890 II , Mass Spectrometer Model 5989 A, Hewlett-Packard, Fuller- 
ton, CA; column Heliflex AT-1, $30 \mathrm{~cm} \times 0.25 \mathrm{~mm} \times 0.2 \mu \mathrm{m}$, Alltech, Deerfield, IL). $\beta$-Phenyl-glucose was used as internal standard [18] [intraassay coefficient of variation of 1 to $4 \%$, interassay coefficient of variation 1.5 to $5 \%$; detection limit, $1.5 \mathrm{mM}$ (0.5\% enriched)].

\section{Statistical Analysis and Calculations}

All values are expressed as means \pm SEM. The data were analyzed by two-way (i.e., group and time) analysis of variance for repeated measurements and the Newman-Keuls test for post hoc testing. For comparison between the two sampling sites of cytokines within each group the Wilcoxon test for paired samples was used. A P value $<$ 0.05 was considered to be statistically significant.

Systemic vascular resisitance (SVR) was calculated using the following formula [12]: SVR $=[(\mathrm{MABP}-\mathrm{CVP}) \times 80] / C O$, where MABP is mean arterial blood pressure $(\mathrm{mm} \mathrm{Hg})$, CVP is central venous pressure $(\mathrm{mm} \mathrm{Hg})$, and $\mathrm{CO}$ is cardiac output (liters/min). SVR is given as $\times 10^{4} \mathrm{dyn} \cdot \mathrm{s} \mathrm{cm} \mathrm{cm}^{-5}$. Net hepatic TNF and IL-6 production was calculated using the following formula: net hepatic cytokine production $=\left(\mathrm{Q}_{\mathrm{HV}} \times \mathrm{C}_{\mathrm{HV}}\right)-\left[\left(\mathrm{Q}_{\mathrm{PV}} \times \mathrm{C}_{\mathrm{PV}}\right)+\left(\mathrm{Q}_{\mathrm{HA}} \times \mathrm{C}_{\mathrm{FA}}\right)\right]$, where $\mathrm{Q}_{\mathrm{HV}}$, $\mathrm{Q}_{\mathrm{PV}}$, and $\mathrm{Q}_{\mathrm{HA}}$ are blood flow through the hepatic vein, portal vein, and hepatic artery, and $\mathrm{C}_{\mathrm{HV}}, \mathrm{C}_{\mathrm{PV}}$, and $\mathrm{C}_{\mathrm{FA}}$ are cytokine concentrations in the hepatic vein, portal vein and femoral artery, respectively. Net hepatic cytokine production is given in nanograms per minute. The non-steady-state equations were used to cal culate the rate of appearance $\left(R_{a}\right)$ of glucose as adapted for the use of stable isotopes [19].

\section{RESULTS}

\section{Temperature}

Basal temperature was slightly higher in awake dogs $\left(38.2 \pm 0.1^{\circ} \mathrm{C}\right)$ versus anesthetized dogs (peripheral, $36.2 \pm 0.4^{\circ} \mathrm{C}$; portal $\left.35.9 \pm 0.4^{\circ} \mathrm{C} ; \mathrm{P}<0.05\right)$. Endotoxin increased the temperature in the conscious dogs to a maximum $40.6 \pm 0.5^{\circ} \mathrm{C}(\mathrm{P}<0.01)$, but did not affect the temperature in anesthetized dogs.

\section{Hemodynamics}

Endotoxin induced a hyperdynamic response in the circulation of anesthetized dogs (Fig. 1). Cardiac output increased transiently by $30-35 \%$ ( $P<0.05$ vs basal) in both groups to a peak value at $60 \mathrm{~min}$ after endotoxin administration. The route of endotoxin administration did not affect the hemodynamic responses to endotoxin. Systemic vascular resistance decreased after endotoxin to a nadir at $60 \mathrm{~min}$ (peripheral group from $0.39 \pm 0.04$ to $0.27 \pm 0.02 \times 10^{4} \mathrm{dyn} \cdot \mathrm{s} \mathrm{cm}^{-5}$; portal group from $0.44 \pm 0.04$ to $0.29 \pm 0.03 \times 10^{4} \mathrm{dyn} \cdot \mathrm{s} \mathrm{cm}^{-5} ; \mathrm{P}<0.05$ vs basal; NS between both groups). Total hepatic blood flow (basal: $9.0 \pm 0.6 \mathrm{ml} / \mathrm{kg} \cdot \mathrm{min}$ vs $8.1 \pm 0.4 \mathrm{ml} /$ $\mathrm{kg} \cdot \mathrm{min}$, respectively) was not affected by portal or systemic endotoxin administration. In awake dogs endotoxin resulted in a transient increase in blood pressure ( $P<0.05$ vs anesthetized dogs).

\section{Cytokines}

In anesthetized dogs peak arterial levels of TNF were reached 60 min after endotoxin administration, with a gradual decline to baseline afterward (portal group, from below detection limit to $5 \pm 2 \mathrm{ng} / \mathrm{ml}$, vs peripheral group, from below detection limit to $6 \pm 2 \mathrm{ng} / \mathrm{ml}$, both $\mathrm{P}<0.01$ vs basal) (Fig. 2). Arterial levels of TNF were not affected by the route of endotoxin administration.
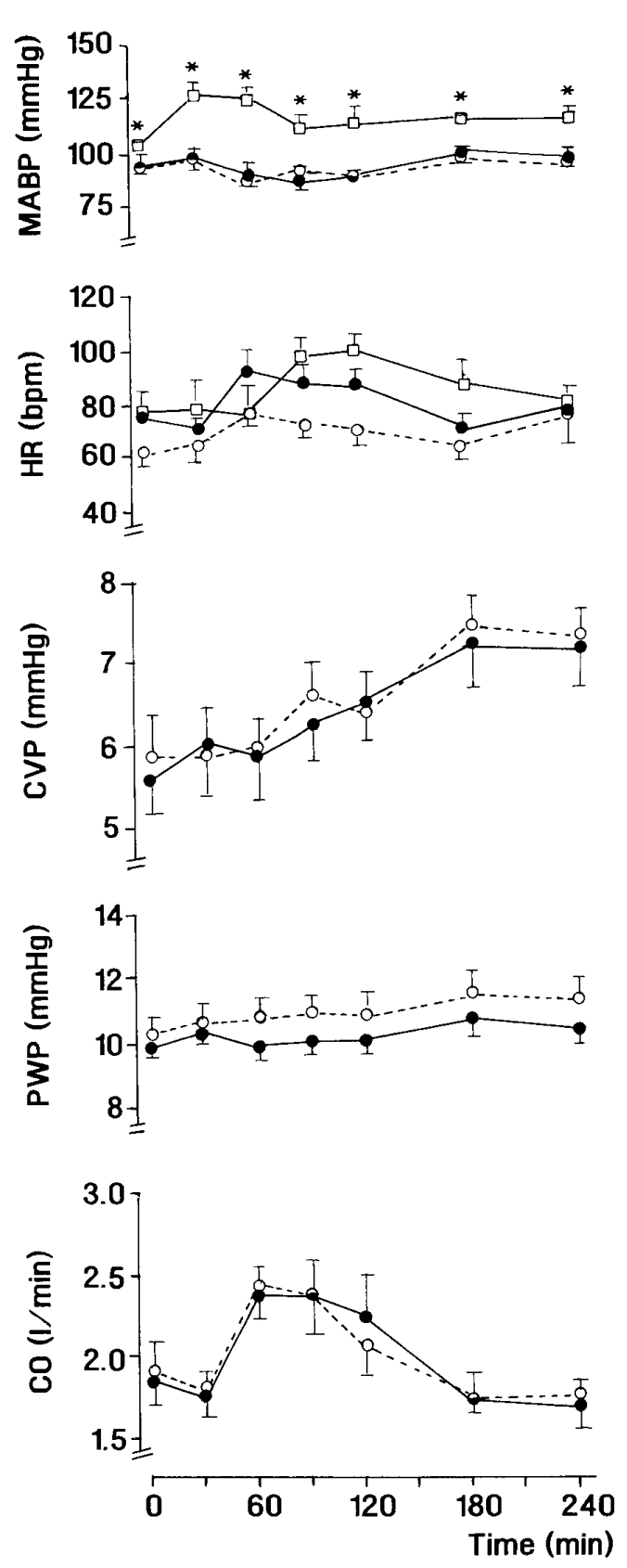

FIG. 1. Hemodynamic parameters before and after administration of $1.0 \mu \mathrm{g} / \mathrm{kg}$ endotoxin into a cephalic vein $(\bigcirc)$ or into the portal vein $(\bullet)$ in anesthetized dogs and into a cephalic vein in awake dogs $(\square)$. MABP, mean arterial blood pressure; HR, heart rate; CVP, central venous pressure; PWP, wedge pressure; $C O$, cardiac output. Swan Ganz measurements were not obtained in control dogs. All values are given as means $\pm \mathrm{SEM} . * \mathrm{P}<0.05$ between awake and anesthetized dogs. There were no differences between both anesthetized groups. Cardiac output was significantly increased 60-90 min after endotoxin administration in both anesthetized groups $(\mathrm{P}<$ 0.05). MABP was significantly higher in awake dogs compared with anesthetized dogs.

There was no net hepaticTNF production prior to endotoxin administration. However, net hepatic TNF production increased significantly after endotoxin administration in both groups (NS between groups) (Table 1). Data on plasma TNF levels were not obtained in the conscious dogs, because these plasma samples were 

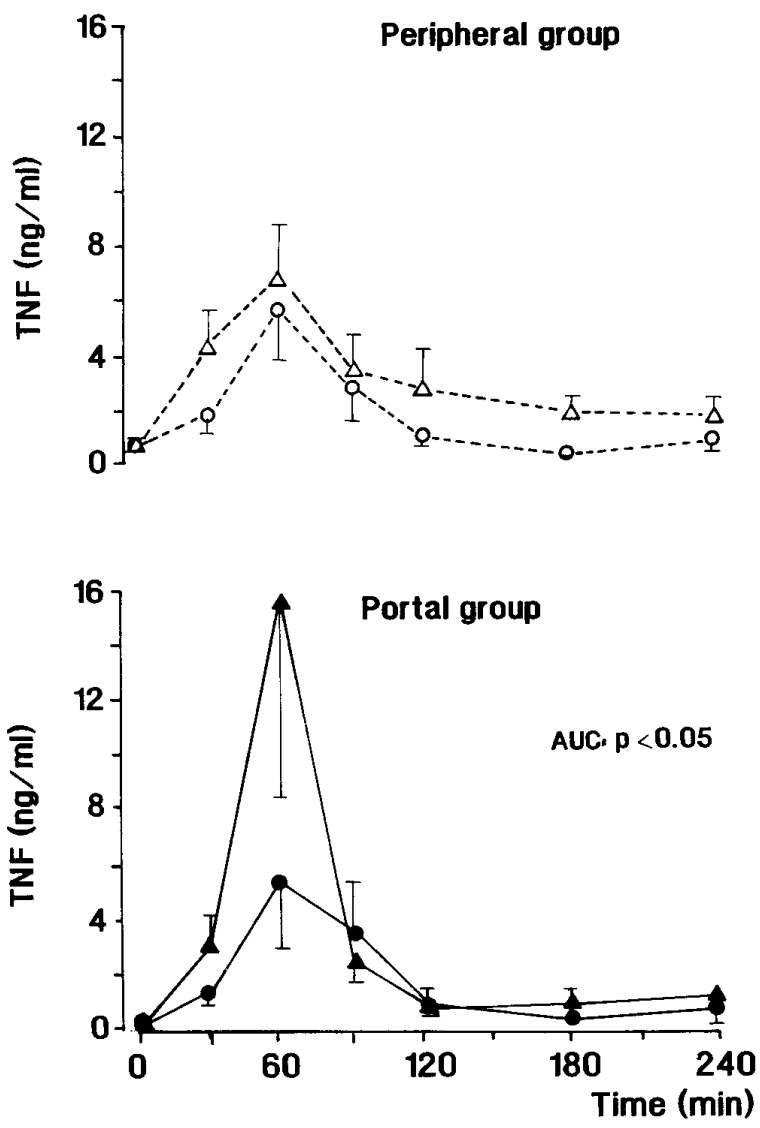

FIG. 2. Plasma TNF levels ( $\mathrm{ng} / \mathrm{ml}$ ) in the femoral artery (circles) and hepatic vein (triangles) before and after administration of 1.0 $\mu \mathrm{g} / \mathrm{kg}$ endotoxin into a cephalic vein or into the portal vein. All values are given as means \pm SEM. There was no difference between the groups. Plasma TNF levels were increased in both groups $(\mathrm{P}<0.01$ vs basal). Plasma TNF levels were higher in the hepatic veins than in the femoral artery after portal endotoxin administration but not after peripheral endotoxin administration.

thawed by accident and therefore we could not obtain reliable plasma TNF levels.

Endotoxin administration increased arterial plasma IL-6 concentrations in all dogs, with peak levels 180 min after endotoxin administration (portal group, from $2 \pm 1$ to $95 \pm 14 \mathrm{ng} / \mathrm{ml}$, vs peripheral group, from $2 \pm$
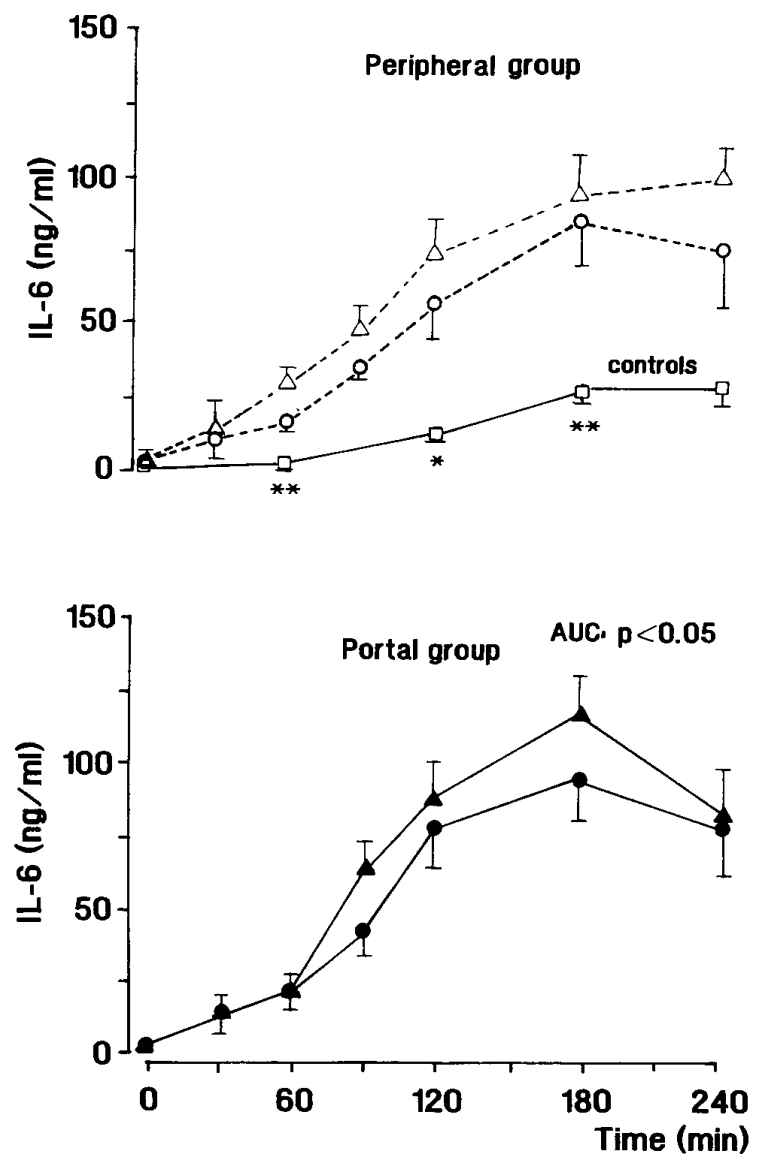

FIG. 3. Plasma IL-6 levels (ng/ml) in the femoral artery (circles) and hepatic vein (triangles) before and after administration of 1.0 $\mu \mathrm{g} / \mathrm{kg}$ endotoxin into a cephalic vein or into the portal vein. All values are given as means \pm SEM. There was no difference between the groups. Plasma IL-6 levels were increased in both groups $(P<0.01$ vs basal). Plasma IL-6 levels were higher in the hepatic veins than in the femoral artery after portal endotoxin administration (AUC: P $<0.05$ ), but not after peripheral endotoxin administration.

1 to $86 \pm 15 \mathrm{ng} / \mathrm{ml}$, both $\mathrm{P}<0.01$ vs basal) (Fig. 3). The route of administration did not influence the arterial IL-6 concentrations in the anesthetized dogs, but the values were about three times higher in the anesthetized dogs compared with the awake dogs (awake

TABLE 1

Net Hepatic TNF and IL-6 Balance (ng/min) before and after Administration of $1.0 \mu \mathrm{g} / \mathrm{kg}$ Endotoxin into a Cephalic (C) or the Portal (P) Vein in Anesthetized Dogs ${ }^{a}$

Time (min)

\begin{tabular}{|c|c|c|c|c|c|c|c|}
\hline & \multicolumn{7}{|c|}{ Time (min) } \\
\hline & 0 & 30 & 60 & 90 & 120 & 180 & 240 \\
\hline \multicolumn{8}{|l|}{ TNF } \\
\hline C & $3 \pm 77$ & $533 \pm 177 *$ & $216 \pm 154$ & $-395 \pm 323$ & $202 \pm$ & $180 \pm 145$ & $97 \pm 151$ \\
\hline $\mathrm{P}$ & $7 \pm 11$ & $416 \pm 274$ & $2135 \pm 1127 *$ & $-36 \pm 374$ & $82 \pm$ & $147 \pm 128$ & $152 \pm 171$ \\
\hline \multicolumn{8}{|l|}{ IL-6 } \\
\hline C & $319 \pm 194$ & $311 \pm 421$ & $1403 \pm 921$ & $2419 \pm 1384$ & $950 \pm 2838$ & $-2060 \pm 3294$ & $-1573 \pm 2313$ \\
\hline$P$ & $86 \pm 129$ & $-262 \pm 427$ & $927 \pm 1195$ & $4740 \pm 1899 *$ & $587 \pm 1220$ & $2622 \pm 2973$ & $-3100 \pm 2376$ \\
\hline
\end{tabular}

${ }^{a}$ Values are given as means \pm SEM.

$* \mathrm{P}<0.05$ vs basal values. There were no significant differences between groups. 
dogs, from below detection limit to $27 \pm 3 \mathrm{ng} / \mathrm{ml}, \mathrm{P}<$ 0.01 vs basal; $P<0.05$ vs both anesthetized groups). There was no net hepatic I L-6 production prior to endotoxin administration. Net hepatic IL-6 production was stimulated after portal, but not after peripheral, endotoxin administration ( $\mathrm{P}<0.05$ vs basal)(ns between groups) (Table 1).

\section{Glucoregulatory Hormones}

Plasma concentrations of glucoregulatory hormones are shown in Fig. 4. The route of endotoxin did not
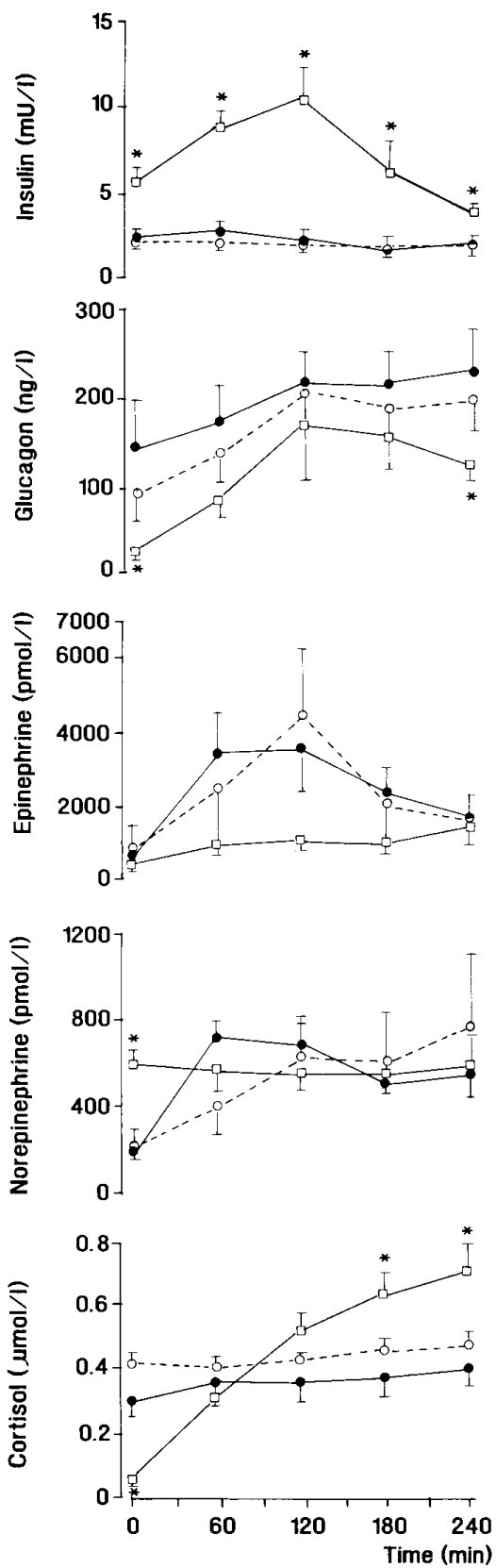

FIG. 4. Arterial plasma concentrations of insulin ( $\mathrm{mU} / \mathrm{liter}$ ), glucagon (ng/liter), epinephrine (pmol/liter), norepinephrine (pmol/liter) and cortisol $(\mu \mathrm{mol} / \mathrm{liter})$ after endotoxin injection $(1.0 \mu \mathrm{g} / \mathrm{kg})$ into a cephalic $(O)$ or the portal $(\bullet)$ vein in anesthetized dogs and into a cephalic vein in awake dogs $(\square)$. Values are given as means \pm SEM. There were no differences between both anesthetized groups. ${ }^{*} \mathrm{P}<$ 0.05 between awake and anesthetized dogs.
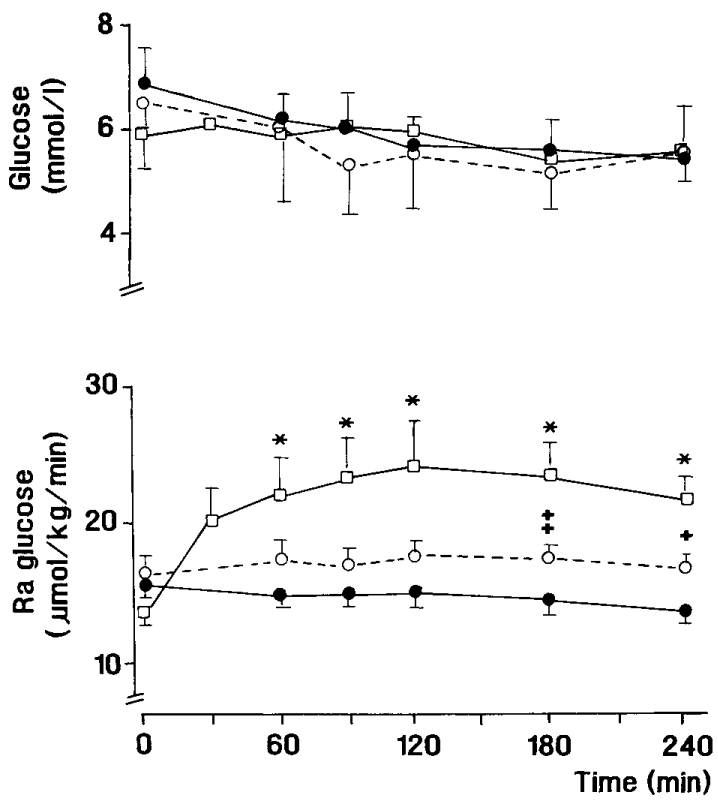

FIG. 5. Arterial plasma levels (mmol/liter) and rate of appearance $\left(R_{a}\right)$ of glucose $(\mu \mathrm{mol} / \mathrm{kg} \cdot \mathrm{min})$ before and after bolus injection of endotoxin $(1.0 \mu \mathrm{g} / \mathrm{kg})$ into a cephalic $(\mathrm{O})$ and the portal $(\bullet)$ vein in anesthetized dogs and into a cephalic vein in awake dogs ( $\square$ ). Values are given as means \pm SEM. $* P<0.05$ between awake and anesthetized dogs, ${ }^{+} \mathrm{P}<0.05$ between both anesthetized groups, ${ }^{++} \mathrm{P}$ $=0.06$ between both anesthetized groups.

affect the neuroendocrine response to endotoxin in the anesthetized dogs.

Prior to injection of endotoxin, concentrations of cortisol and glucagon were higher in anesthetized dogs, whereas insulin and norepinephrine levels were lower compared with awake dogs ( $P<0.05)$. Endotoxin stimulated insulin secretion only in awake dogs $(P<0.05)$, whereas glucagon secretion was increased in all three groups (NS between groups). There was a variable response of (nor)epinephrine to endotoxin within each group (NS between groups). Cortisol concentrations did not change after endotoxin in anesthetized dogs, whereas cortisol increased to higher values within $3 \mathrm{~h}$ of endotoxin in awake dogs compared with anesthetized dogs $(P<0.01)$.

\section{Glucose Kinetics}

Plasma concentrations and rates of appearance of glucose are shown in Fig. 5. Basal plasma glucose concentrations were not different between the three groups. Basal rate of appearance of glucose was not different in the three groups (conscious dogs: $13.8 \pm$ $1.2 \mu \mathrm{mole} / \mathrm{kg} \cdot \mathrm{min}$; anesthetized dogs: peripheral group, $16.5 \pm 1.3 \mu \mathrm{mole} / \mathrm{kg} \cdot \mathrm{min}$, and portal group, 15.8 $\pm 1.1 \mu \mathrm{mole} / \mathrm{kg} \cdot \mathrm{min}) . \mathrm{In}$ anesthetized dogs, peripheral injection of endotoxin did not influence $R_{a}$ glucose (16.8 $\pm 1.2 \mu \mathrm{mole} / \mathrm{kg} \cdot \mathrm{min}$ at $240 \mathrm{~min})$, whereas a significant decrease was found after intraportal injection (13.6 \pm $0.9 \mu \mathrm{mole} / \mathrm{kg} \cdot \mathrm{min}$ at $240 \mathrm{~min} ; \mathrm{P}<0.05 \mathrm{vs}$ peripheral endotoxin administration). In contrast, endotoxin induced a considerable rise of $\sim 75 \%$ in glucose produc- 
tion in the awake dogs ( $\mathrm{P}<0.05$ vs basal; $\mathrm{P}<0.05$ vs anesthetized dogs).

\section{DISCUSSION}

This study indicates that the inflammatory and metabolic effects of endotoxin are in part dependent on the route of endotoxin delivery. Although intraportal injection of endotoxin stimulated hepatic TNF and IL6 production, and peripheral injection of endotoxin stimulated only hepatic TNF but not hepatic IL-6 production, there were no differences in cytokine responses between both groups. N onetheless, hepatic glucose production decreased after portal endotoxin administration but not after peripheral delivery of endotoxin. The combination of surgery and anesthesia increased the IL-6 response and modulated the neuroendocrine response to endotoxin, associated with the absence of the normal stimulation of hepatic glucose production to endotoxin. Therefore, the effects of endotoxin, at least with respect to glucose production, are dependent on the site of entry into the circulation. Moreover, the effects of endotoxin are altered by the combination of surgery and anesthetic agents.

TNF and IL-6 levels were considerably increased after endotoxin administration. In accordance with the literature, the increase in plasma IL-6 levels was preceded by a rise in plasma TNF levels [7, 13]. There were no differences in plasma cytokine levels in relation to the origin of endotoxin. However, in accordance with previous observations, there was a large variability in cytokine responses to endotoxin within each group [20]. We cannot exclude the possibility that the detection of differences in cytokine production between both anesthetized groups is precluded by this large within-group variability.

The effects of the route of endotoxin administration were studied in anesthetized dogs. In these dogs a laparotomy was performed on the day of the study for cannulation of the hepatic vessels. Therefore, the inflammatory, neuroendocrine, and metabolic effects in these dogs were affected by the combination of surgery, anesthesia, and endotoxin. However, this combination of factors does not invalidate our conclusions with respect to portal versus peripheral delivery of endotoxin, because the circumstances were identical for both groups of anesthetized dogs except for the route of endotoxin administration.

Hepatic glucose production was stimulated considerably by peripheral endotoxin administration in awake dogs, in contrast to anesthetized, operated dogs. The metabolic changes induced by endotoxin are thought to be mediated at least in part by the induction of TNF and IL-6. Administration of IL-6 and TNF increases glucose production in dogs and humans in association with neuroendocrine activation [21-25]. However, despite the considerable response of TNF and IL-6, the stimulatory effects of endotoxin on hepatic glucose production were absent in anesthetized dogs. There were differences in endotoxin-induced neuroendocrine acti- vation between awake and anesthetized dogs. Although insulin and norepinephrine levels were higher in awake dogs, cortisol and glucagon concentrations were higher in anesthetized dogs. Therefore, we cannot exclude the possibility that the discrepancy in the effects of endotoxin on glucose production between awake and anesthetized dogs are related to these differences in neuroendocrine activation.

Portal administration of endotoxin decreased hepatic glucose production in anesthetized dogs. This effect was not caused by differences in secretion of glucoregulatory hormones, because there were no endocrine differences between both groups of anesthetized dogs. It has been suggested that the hepatic response to endotoxin involves the release of inflammatory mediators, like cytokines from Kupffer cells which interact with hepatocytes to induce nitricoxide production [26]. Recent studies have provided evidence that nitric oxide may be an inhibitory mediator of the effects of endotoxin on hepatic glucose production [27, 28]. Endotoxin exposure and clearance are higher after portal then after peripheral endotoxin delivery [4]. It is possible that in our study the degree of hepatic endotoxin exposure, which is higher after portal then after peripheral endotoxin delivery, altered glucose production by intrahepatic mechanisms like nitric oxide rather than by endocrine mechanisms. Hasibeder et al. studied the effects of systemic versus mesenteric artery infusion of endotoxin in circulatory stable pigs [29]. I nterestingly, they found that mucosal mirovascular dysfunction is dependent largely on the local microvascular endotoxin concentration, supporting the hypothesis that local mechanisms are important in the reaction to endotoxin.

In summary, there are no major differences in the responses to endotoxin between peripherally treated and portally treated dogs, except for minor differences in glucose production. The glucoregulatory response to endotoxin is altered by the site of entry of endotoxin into the circulation, probably through nonendocrine mechanisms. The inflammatory, neuroendocrine, and metabolic effects of endotoxin are altered by the combination of surgery and anesthesia.

\section{ACKN O WLEDGMENTS}

We thank C. W. J . Verlaan, M. G. Klein, and M. A. T. van de Berg for their excellent technical assistance and the Laboratory of Endocrinology for their expert analytical support. We also thank R. W. Sauerwein from the Department of Microbiology (University Hospital, Nijmegen, The Netherlands) for his support and advice with the WEHI assay.

J. A. Romijn is a clinical investigator supported by the Dutch Organisation for Scientific Research (NWO) and the Dutch Diabetes Organisation.

\section{REFERENCES}

1. Abel, F. L., and Beck, R. R. Portal venous compliance in canine endotoxin shock. Circ. Shock 35: 96, 1991.

2. Augsten, T. R., Chen, M. K., Flynn, T. C., and Souba, W. W. The effects of endotoxin on the splanchnic metabolism of glutamine and related substrates. J . Trauma 31: 742, 1991. 
3. Beyerley, L. O., Alcock, N. W., and Starnes, F. S. Sepsis-induced cascade of cytokine mRNA expression: Correlation with metabolic changes. Am. J . Physiol. 261: E728, 1992.

4. Bottoms, G. D., Gimarc, S., and Pfeifer, C. Plasma concentrations of endotoxin following jugular or portal injections of endotoxin and following gastrointestinal ischemia due to hemorrhage. Circ. Shock 33: 1, 1991.

5. Breuille, D., Rose, F., Arnal, M., Melin, C., and Obled, C. Sepsis modifies the contribution of different organs to whole-body protein synthesis in rats. Clin. Sci. 86: 663, 1994.

6. Caruana, J . A., Camara, D. S., Schneeberger, G. J ., and Nolan, J.P. The clearance capacity of canine liver for a portal vein endotoxin infusion. J . Surg. Res. 37: 197, 1984.

7. Fong, Y., Marano, M.A., Moldawer, L. L., Wei, H., Calvano, S. E., Kenney, J.S., Allison, A. C., Cerami, A., Shires, G. T., and Lowry, S. F. The acute splanchnic and peripheral tissue metabolic response to endotoxin in humans. J . Clin. Invest. 85: 1896, 1990.

8. Halvorsen, L., Roth, R., Gunther, R. A., Firoozmand, E., Buoncristiani, A. M., and Kramer G. C. Liver hemodynamics during portal venous endotoxemia in swine. Circ. Shock 41: 166, 1993.

9. Ra Ling, P., Bistrian, B. R., Mendez, B., and Istfan, N. W. Effects of systemic infusions of endotoxin, tumor necrosis factor, and interleukin-1 on glucose metabolism in the rat: Relationship to endogenous glucose production and peripheral tissue glucose uptake. Metabolism 43: 279, 1994.

10. Wolfe, R. R., Elahi, D., and Spitzer, J.J. Glucose and lactate kinetics after endotoxin administration in dogs. Am. J . Physiol. 232: E 180, 1977.

11. Gans H. RES control of endotoxemia. In S. M. Reichard and J . P. Filkins (Eds.), The Reticuloendothelial System. New York: Plenum Press, 1989. Pp. 115- 143.

12. Navaratnam, R. L. N., Morris, S. E., Traber, D. L., Flynn, J ., Woodson, L., Linares, H., and Herndon, D. N. Endotoxin increases mesenteric vascular resistance and bacterial translocation. J . Trauma 30: 1104, 1990.

13. LeMay, D. R., LeMay, L. G., Kluger, M. J ., and D'Alecy, L. G. Plasma profiles of IL-6 and TNF with fever-inducing doses of LPS in dogs. Am. J . Physiol. 259: R126, 1990.

14. Ishida, T., Lewis, R. M., Hartley, C.J ., Entman, M. L., and Field, J . B. Comparison of hepatic extraction of insulin and glucagon in conscious and anesthetized dogs. Endocrinology 112: 1098, 1983.

15. Smedes, F., Kraak, J . C., and Poppe, H. Simple and fast solvent extraction system for selective and quantitative isolation of adrenalin, noradrenaline and dopamine for plasma and urine. J . Chromatogr. 231: 25, 1982.

16. Espevik, T., and Nissen-Meyer, J . A highly sensitive cell line,
WEHI 164 subclone 13, for measuring cytotoxic facor tumor necrosis factor from human monocytes. J . Immunol. Methods 95: 99, 1986.

17. Helle, M., Boeye, L., and Aarden, L. A. Functional discrimination between IL-6 and IL-1. Eur. J . Immunol. 18: 1535, 1988.

18. Reinhauer, H., Gries, F. A, Hubinger, A., Knode, O., Severing, K., and Susanto, F. Determination of glucose turnover and glucose oxidation rates in man with stable isotope tracers. J . Clin. Chem. Clin. Biochem. 28: 505, 1990.

19. Rosenblatt, J . I., and Wolfe, R. R. Calculation of substrate flux using stable isotopes. Am. J . Physiol. 254: E526, 1988.

20. Michie, H. R., Manogue, K. R., Spriggs, D. R., Revhaug, A., O'Dwyer, S., Dinarello, C. A., Cerami, A., Wolff, S. M., and Wilmore, D. W. Detection of circulating tumor necrosis factor after endotoxin administration. N. Engl. J . Med. 318: 1481, 1988.

21. Stouthard, J . M. L., Romijn, J . A., van der Poll, T., Endert, E., Klein, S., Bakker, P. J . M., Veenhof, C. H. N., and Sauerwein, H. P. Endocrine and metabolic effects of interleukin-6 in humans. Am. J . Physiol. 268: E 813, 1995.

22. Van der Poll, T., Romijn, J . A., Endert, E., Borm, J .J . J , Büller, H. R., and Sauerwein, H.P. Tumor necrosis factor mimics the metabolic response to acute infection in healthy humans. Am. J . Physiol. 261: E457, 1991.

23. Lang, C. H., Dobrescu, C., and Bagby, G. J . Tumor necrosis factor impairs insulin action on peripheral glucose disposal and hepatic glucose output. Endocrinology 130: 43, 1992.

24. Sakurai, Y., Zhang, X. U., and Wolfe, R. R. Short-term effects of tumour necrosis factor on energy and substrate metabolism in dogs. J . Clin. Invest. 91: 2437, 1993.

25. Ritchie, D. G. Interleukin 6 stimulates hepatic glucose release from prelabeled glycogen pools. Am. J . Physiol. 258: E57, 1990.

26. Curran, R. D., Billiar, T.R., Stuehr, D. J ., Ochoa, J.B., Harbrecht, B. G., Flint, S. G., and Simmons, R. L. Multiple cytokines are required to induce hepatocyte nitric oxide production and inhibit protein synthesis. Ann. Surg. 21: 462, 1990.

27. Horton, R. A., Ceppi, E. D., Knowles, R. G., and Titheradge, M. A. Inhibition of hepatic gluconeogenesis by nitric oxide: $A$ comparison with endotoxic shock. Biochem. J . 299: 735, 1994.

28. Stadler, J., Barton, D., Beil-Moeller, H., Diekmann, S., Hierholzer, C., Erhard, W., and Heidecke, C. Hepatocyte nitric oxide biosynthesis inhibits glucose output and competes with urea synthesis for L-arginine. Am. J . Physiol. 268: G183, 1995.

29. Hasibeder, W., Germann, R., Wolf, H. J ., Haisjackl, M., Hausdorfer, H., Riedmann, B., Bonatti, J ., Gruber, E., Schwarz, B., Waldenberger, P., Friesenecker, B., and Furtner, B. Effects of short-term endotoxemia and dopamine on mucosal oxygenation in porcine jejunum. Am. J . Physiol. 270: G667, 1996. 